\title{
O SISTEMA INTERAMERICANO E A PROTEÇÃO DOS DIREITOS HUMANOS DA MULHER:
}

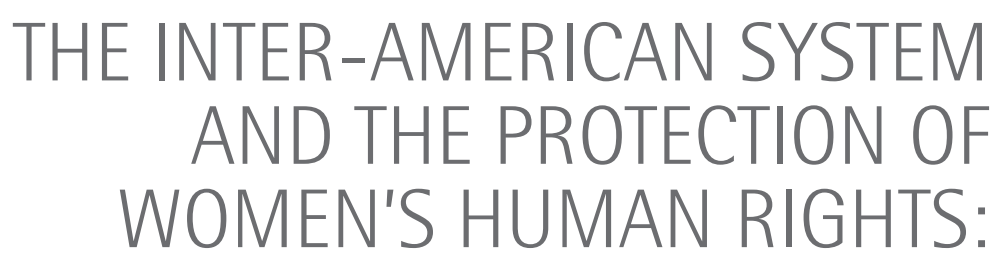

MONITORING PETITIONS AGAINST BRAZIL (2006-15).

Ianá Priscilla de Oliveira Silva priscilla.iana@hotmail.com

Alessandra Marchioni alemarchioni@hotmail.com

Recebido: 30-6-2017

Aprovado: 12-11-2018

SUMÁRIO: 1 Introdução. 2 Panorama da proteção internacional dos direitos humanos da mulher. 3 Convenção Americana de Direitos Humanos (Pacto de San José da Costa Rica) e os seus dispositivos de monitoramento e controle. $4 \mathrm{O}$ sistema de monitoramento da Convenção Americana de Direitos Humanos/1969 e as petições individuais em matéria de direitos humanos das mulheres - análise dos relatórios (2006-2015). 5 Consideraçóes finais. 6 Referências.

\section{RESUMO:}

Esse artigo contextualiza o desenvolvimento dos direitos humanos das mulheres na contemporaneidade, enfatizando o sistema regional de proteção e a Convenção Americana de Direitos Humanos/1969. Nesse contexto, são identificados os direitos específicos relativos à proteção da mulher e os órgãos de controle administrativo e judicial com competência para processar e deliberar sobre as demandas propostas. Esse trabalho tem como objetivo investigar a hipótese de que o sistema de petiçóes individuais ou queixas (individual complaints) propostas junto à Comissão Interamericana de Direitos Humanos é

\section{ABSTRACT:}

This article contextualize the development of human rights of women in contemporary society, with emphasis on regional human rights system and the American Convention on Human Rights/1969. In this context, the specific rights relating to the protection of women and the administrative and judicial bodies with powers to process and act on the demands proposals are identified. This work aims to investigate the hypothesis that the system of individual petitions or complaints (individual complaints) proposed by the Inter-American Commission on Human Rights is control and monitoring mechanisms able to mirror the situation 
mecanismo de controle e monitoramento capaz de espelhar a situação de violação de direitos contra a mulher no país, podendo funcionar como instrumento alternativo à garantia dos direitos humanos.

\section{PALAVRAS-CHAVE:}

Direitos Humanos. Mulher. Petiçóes individuais. Comissão Interamericana de Direitos Humanos of rights violations against women in the country and can act as alternative instruments to guarantee human rights.

\section{KEY WORDS:}

Human rights. Woman. Individual petitions. Inter-American Commission on Human Rights

\section{INTRODUÇÃO}

Ao longo das últimas cinco décadas, os direitos humanos se converteram em um tema de interesse internacional, afirmando-se como um ramo autônomo do direito dotado de especificidade própria, inclusive enquanto problema de estudo e pesquisa. Entretanto, se bem que os direitos humanos tenham conhecido essa impressionante evolução através de tratados e convençóes internacionais, continuam a produzir uma eficácia limitada sob o ponto de vista do cumprimento de suas obrigaçóes e garantias (TRINDADE,1991).

Em seu processo de "juridicização", os Pactos Internacionais de Direitos Humanos $(1969)^{1}$, também conhecidos como International Bill of Rights, inauguraram o sistema global de proteção dos direitos civis, políticos, sociais, econômicos e culturais, em simultaneidade à criação dos sistemas de proteção em âmbito regional, como o interamericano (PIOVESAN, 2000).

O sistema global dos direitos humanos viria a ser ampliado, em seu conjunto, com a introdução de outros tratados multilaterais que garantiram, em espécie, a proteção contra violaçốes de direitos, como a eliminação de discriminação contra a mulher. A Convenção sobre Eliminação da Discriminação contra a Mulher (1979), aderida pelo Brasil em 1984, não apenas objetivava erradicar a discriminação contra a mulher e suas causas, como também estimular estratégias de promoção de igualdade entre os gêneros.

Porém, embora tenha evoluído em relação ao cenário de proteção de direitos específicos, não enfrentou com clareza a temática da violência contra a mulher, o que somente ocorreu com a Convenção Interamericana para Prevenir, Punir e Erradicar a Violência contra a Mulher (1994).

Neste contexto, frise-se que nenhum deles tem competência para sancionar um Estado-parte que viole a convenção. Desta forma, em adição aos mecanismos originais de monitoramento e controle definidos pelas convençôes internacionais, a Convenção Americana de Direitos Humanos (1969) prevê mecanismos complementares àqueles relativos à entrega de relatórios periódicos, viabilizando as denúncias de violaçóes de direitos sob a forma de petiçóes individuais ou queixas pelos indivíduos, grupos de indivíduos ou organizações não governamentais.

\footnotetext{
1 Por certo, a Declaração Universal dos Direitos Humanos (1948) aprovada pela Assembleia Geral das Nações Unidas, teve papel fundamental na definição e fixação desse elenco mínimo de direitos e liberdades fundamentais a serem garantidos.
} 
Com efeito, tomando por base os dados estatísticos do UNA-SE e da UNFPA sobre violência contra a mulher, incluindo os índices do $\mathrm{PNAD}^{2}$ nacional, esse artigo tem como objetivo principal investigar a hipótese de que o sistema de petiçóes individuais ou queixas (individual complaints), previsto na Convenção Americana, e propostas junto à Comissão Interamericana, seja um mecanismo de controle e monitoramento capaz de espelhar a situação de violação de direitos contra a mulher no país, podendo funcionar como instrumentos alternativos de solução e garantia dos direitos humanos.

Para tanto, será apresentado um panorama das principais convençôes internacionais sobre a proteção dos direitos humanos da mulher, seguido da descrição do sistema regional americano, desde a identificação dos direitos e garantias protegidos até a previsão e monitoramento de competências dos órgãos interamericanos. Por último, será realizado um levantamento dos informes da Comissão Interamericana contra o Estado brasileiro, em matéria de violação ao direito da mulher, impetradas no período de 2006 a 2015.

\section{PANORAMA DA PROTEÇÃO INTERNACIONAL DOS DIREITOS HUMANOS DA MULHER}

Ao final de cinco décadas de extraordinária evolução, o direito internacional dos direitos humanos afirma-se como um ramo autônomo do direito dotado de especificidade própria. Trata-se essencialmente de um direito de proteção dos seres humanos, formado pelo conjunto de normas e uma série de mecanismos de supervisão e controle que lhe são próprios (COMPARATO, 2003).

Desse modo, diferentemente dos tratados em geral, nos tratados de direitos humanos a chamada autonomia de vontade estatal cede espaço à fiel realização de objetivos e propósitos por seus valores éticos e morais, que buscam ampliar a proteção de direitos em relação à vítima (PIOVESAN, 2000). Assim, é que os tratados internacionais em matéria de direitos humanos estabelecem pelo menos duas esferas de proteção distintas e complementares à nacional, uma em âmbito global e outra em caráter regional, respectivamente sujeitos aos sistemas das Organizaçóes das Naçóes Unidas e dos Estados Americanos.

Neste sentido, o critério de seleção da norma aplicável deverá utilizar o critério da primazia da norma mais benéfica às pessoas protegidas (TRINDADE, 1991). Ao que pese ambas as normativas internacionais serem sistemas complementares ao nacional, pode-se identificar uma clara inflexão não judicial de solução de controvérsias no sistema onusiano, à diferença do sistema interamericano que prevê uma solução predominantemente judicial. (PIOVESAN, 2000)

Em 1979, impulsionada pela proclamação em 1975 do Ano Internacional da Mulher e pela Conferência Internacional da Mulher do mesmo ano, as Naçôes Unidas aprovaram a Convenção sobre a eliminação de todas as formas de discriminação contra a mulher. Se bem que amplamente aceita pela comunidade internacional, na época, mais de 100 ratificaçóes,

$2 \quad$ Até o primeiro semestre de 2012, foram feitos 47.555 registros de atendimento na Central de Atendimento à Mulher. Durante todo o ano de 2011, foram 74.984 registros, bem inferior aos 108.491 de 2010. 0 tipo de registro que aparece em maior número é para relatar violência física contra a mulher que pode variar de lesão corporal leve, grave ou gravíssima, tentativa de homicídio e homicídio consumado. Foram 63.838 em 2010, 45.953 em 2011 e 26.939 até julho de 2012. Casos de violência sexual como estupro, exploração sexual e assédio no trabalho aparecem em 50 lugar com 2.318 casos em 2010, 1.298 em 2011 e 915 este ano. 
enfrentou o paradoxo de ser o instrumento internacional de proteção que mais recebeu número de reservas substanciais ${ }^{3}$.

Nesses termos, ressalta-se que em matéria de proteção à mulher, o Estado brasileiro aderiu esta Convenção Internacional em 1984, com reservas iniciais a alguns dispositivos ${ }^{4}$, depois superadas pelo conteúdo constitucional atual. Segundo o art. 1 da Convenção Internacional a discriminação contra a mulher significa: "toda a distinção, exclusão ou restrição baseada no sexo que tenha por objeto ou resultado prejudicar, anular o reconhecimento, base na igualdade do homem e da mulher, dos direitos humanos e das liberdades fundamentais nos campos político, econômico, social, cultural e civil”. Importa observar que a Convenção Internacional, não enfrenta a temática da violência contra a mulher de forma explícita (AMARAL, 2006).

Diante desse fato, em 1993, as Nações Unidas adotaram a Declaração sobre Eliminação da Violência contra a Mulher, que a definiu como "qualquer ato de violência baseado no gênero. que resulte ou possa resultar em dano físico, sexual ou psicológico ou em sofrimento para a mulher, inclusive as ameaças e atos, coerção ou privação arbitrária da liberdade, podendo ocorrer na esfera pública ou na esfera privada", não aderida pelo Brasil.

No contexto das normas de proteção dos direitos humanos regionais, o país se comprometeu com a Convenção Americana de Direitos Humanos/1969 ou "Pacto de São José da Costa Rica”, aderida em 1992. Esta Convenção não trata especificamente sobre o direito da mulher, mas remete às proteçóes e garantias de liberdades individuais em geral, incluindo o direito à integridade pessoal (art.5) e à liberdade pessoal (art.7).

O país aderiu, em $1995^{5}$, a Convenção Interamericana para Prevenir, Punir e Erradicar a Violência contra a Mulher/1994, também chamada de "Convenção Belém do Pará”. A Convenção Interamericana reconheceu que a violência contra a mulher constitui uma violaçáo aos direitos humanos e às liberdades fundamentais de forma a limitar total ou parcialmente o reconhecimento, gozo e exercício de tais direitos e liberdades, incorporando inúmeros conceitos da Declaração de Viena de 1993 das Nações Unidas. Foi “[...] o tratado com o maior número de ratificaçóes dentro dos sistemas regionais de proteção dos direitos humanos" (NEGREIROS, 2010).

Assim, com base no conteúdo deste direito internacional, em matéria de direitos humanos da mulher, especialmente em matéria de prevenção, coibição e punição de práticas que causem a violência contra a mulher, observa-se a previsão de um conjunto de mecanismos de controle e monitoramento dos tratados que extrapolam os tradicionais relatórios periódicos, elaborados pelos Estados-partes, que são as petiçóes individuais ou queixas (individual complaints).

Com efeito, em função de resultados preliminares, as petições têm sido potentes instrumentos na delação de desobediências por parte do Estado brasileiro ao "Pacto de São José”, como ficou claro no conteúdo da Recomendação 54/2001 da Comissão Interamericana

3 Dos 100 Estados que inicialmente ratificaram o Tratado, 23 realizaram reservas, das quais 88 eram substanciais ao texto. A maior parte das reservas se refere à submissão de controvérsias relativas a interpretação do tratado à jurisdição da Corte Internacional de Justiça (art. 29), outras se referem a adoção de ações afirmativas sobre a eliminação de preconceitos e estereótipos (art. 5) e a eliminação da discriminação na vida política e pública (art. 7). Tais reservas incompatíveis com o objeto e propósito da Convenção contrariam pelo menos a Convenção de Viena sobre Direitos dos Tratados de 1969, em seu art. 19.

$4 \quad 0$ Decreto Legislativo n. 93 de 14 de novembro de 1983 fez reservas aos arts. $15 \S 4$ sobre a liberdade na escolha do domicilio, e ao art. $16 \$ 1$ letras $a_{1}, g_{1}$,e $h$., sobre a igualdade de direitos no casamento e nas relações familiares. 
sobre o caso Maria da Penha. Para confirmar essa hipótese, será realizado um levantamento das açóes perpetradas contra o Estado Brasileiro no período entre 2002-2012 e a análise dos critérios de admissibilidade das petições a partir dos Informes da Comissão Interamericana.

\section{CONVENÇÃO AMERICANA DE DIREITOS HUMANOS (PACTO DE SAN JOSÉ DA COSTA RICA) E OS SEUS DISPOSITIVOS DE MONITORAMENTO E CONTROLE}

A Convenção Americana de Direitos Humanos, negociada em San Jose da Costa Rica em 22/11/1969, entrou em vigor, internacionalmente em 18/07/1978, após o $11^{\text {o }}$ (décimo primeiro) depósito de um instrumento de ratificação ou adesão na SecretariaGeral da Organização dos Estados Americanos, nos termos de seu art. 74-2, entrando em vigor, para os demais Estados, na data do depósito do respectivo instrumento de ratificação ou adesão. Nesse sentido, a Convenção Americana de Direitos Humanos conta com 19 signatários ${ }^{6}$ e 25 instrumentos de ratificação/adesão depositados, dentre o total de 35 (trinta e cinco) países americanos ${ }^{7}$. O Brasil recepcionou o Pacto de San Jose em seu ordenamento em 26.05.1992, através do Decreto Legislativo no 27, de 26.05.1992, e Decreto no 678, de 25.09.1992.

Além de ratificar o Pacto, os Estados puderam reconhecer ou não a competência da Corte Interamericana de Direitos Humanos para todos os casos relativos à interpretação ou aplicação da Convenção (art. 62-1) e a competência da Comissão Interamericana para os casos que envolvam as petiçóes específicas impetradas por Estados-partes contra Estadospartes (art. 45-1). Dentre os 25 países que ratificaram/aderiram ao Pacto, três não aceitaram a competência da Corte $^{8}$ e quinze não aceitaram a competência da Comissão ${ }^{9}$, nos termos anteriormente expostos. Destaque-se que a competência da Comissão para apreciar os casos de violaçóes de Estados contra seus nacionais não depende de declaração expressa, sendo inerente à ratificação do Pacto.

A interpretação do texto da Convenção não pode implicar em supressão, limitação ou exclusão do gozo ou exercício dos direitos nela previstos, excetuando-se os casos de guerra, perigo público ou outra emergência afim (art. 29), nesse último caso, as garantias previstas no Pacto podem ser suspensas por tempo limitado, desde que não encerrem discriminação e, ainda, não alcancem os direitos determinados nos artigos 3 (personalidade jurídica),

6 Dentre os signatários, apenas os Estados Unidos nunca depositaram instrumento de ratificação ou adesão à Convenção. (OEA. CIDH, 2017).

7 Antigua e Barbuda, Bahamas, Belize, Canadá, Cuba, Guiana, São Cristóvão e Neves, Santa Lúcia, São Vicente e Granadinas são os Estados que não assinaram ou aderiram ao Pacto, No caso do Estado cubano, em 2009, durante a 39ª Assembleia Geral da OEA tornou-se sem efeito a Resolução que excluiu Cuba da Organização em 1962, abrindo espaço para sua reintegração. Antes disso, a Comissão Interamericana de Direitos Humanos defendia o posicionamento de que a exclusão do pais, efetivada através da Resolução VI da Oitava Reunião de Consulta de Ministros das Relações Exteriores, compreendia apenas o Governo cubano e não o Estado-membro, ressaltando a diferença entre os conceitos jurídicos de Estado e Governo, mantendo-se o Estado cubano como membro participante do sistema interamericano e, portanto, responsável pelos compromissos assumidos com a Declaração Americana dos Direitos dos e Deveres do Homem e com a Carta da Organização dos Estados Americanos. (OEA. CIDH, 2017).

8 Dominica, Grenada e Jamaica. 0 Peru reconheceu a competência da Corte em 1981, retirou tal reconhecimento em 1999 e voltou reconhecer em 29.01.2001, com vigência ininterrupta a partir do depósito de seu instrumento de ratificação em 21.01.1981. (OEA. CIDH, 2017).

9 Barbados, Bolivia, Brasil, Dominica, El Salvador, Grenada, Guatemala, Haiti, Honduras, México, Panamá, Paraguai, República Dominicana, Suriname e Trinidad e Tobago. (OEA. CIDH, 2017). 
4 (vida), 5 (integridade pessoal), 6 (proibição da escravidão e servidão), 9 (legalidade e retroatividade), 12 (liberdade de consciência e de religião), 17 (proteção à família), 18 (direito ao nome), 19 (direitos da criança), 20 (nacionalidade) e 23 (direitos políticos), nem das garantias indispensáveis a sua proteção, nos termos do que dispóe o art. 27.

Além disso, o texto da Convenção trata sobre a possibilidade de realização de reservas $^{10}$ (art. 75), sobre a possibilidade propositura de emendas ao texto, com submissão de propostas pelos Estados-partes, Comissão ou Corte à Assembleia Geral (art. 76), ou protocolos facultativos, com proposta pelos Estados-partes ou pela Comissão ${ }^{11}$ (art. 77), com vista a incluir outros direitos e liberdades, e sobre a denúncia à Convenção, que pode ocorrer após cinco anos de sua entrada em vigor (art. 78-1 e 78-2) ${ }^{12}$.

A Convenção Americana traz em seu bojo o compromisso firmado entre os Estadospartes para respeitar os direitos e liberdades nela reconhecidos e, ainda, garantir seu pleno e livre exercício a toda pessoa, sem discriminação alguma, por motivo de raça, cor, sexo, idioma, religião, opiniôes políticas ou de qualquer outra natureza, origem nacional ou social, posição econômica, nascimento ou qualquer outra condição social.

Ao todo, o Pacto de São José da Costa Rica elenca 23 (vinte e três) direitos e garantias, distribuídos em 02 (dois) capítulos (II. Dos Direitos Civis e Políticos e III. Dos Direitos Econômicos, Sociais e Culturais) ${ }^{13}$ : Direito ao Reconhecimento da Personalidade Jurídica (art. 3), Direito à Vida (art. 4) $)^{14}$, Direito à Integridade Pessoal (art. 5) ${ }^{15}$, Proibição da Escravidão e da Servidão (art. 6), Direito à Liberdade Pessoal (art. 7), Garantias Judiciais (art. $8)^{16}$, Princípio da Legalidade e da Retroatividade (art. 9), Direito à Indenização (art. 10) ${ }^{17}$,

10 Dos 25 países que aderiram à Convenção, apenas Bolivia, Colômbia, Costa Rica, Equador, El Salvador, Grenada Guatemala, Haiti, Honduras, Jamaica, Nicarágua, Panamá, Paraguai, Suriname não fizeram qualquer reserva ou declaração interpretativa. 0 Brasil realizou apenas uma declaração interpretativa: "O Governo do Brasil entende que os artigos 43 e 48, d, não incluem o direito automático de visitas e investigações in loco da Comissão Interamericana de Direitos Humanos, que dependerão da anuência expressa do Estado". (OEA. CIDH, 2017).

11 A Convenção conta apenas com um protocolo facultativo, o Protocolo Adicional à Convenção Americana sobre Direitos Humanos em Matéria de Direitos Econômicos, Sociais e Culturais - Protocolo de San Salvador (assinado em 17.11.1988), com dezesseis assinaturas e quinze ratificações/adesões. Chile, Haiti, Nicarágua, República Dominicana e Venezuela assinaram, mas não ratificaram, enquanto Brasil, Colômbia, Honduras e Suriname não assinaram, mas ratificaram a posteriori. (OEA. CIDH, 2017).

12 Nesses termos, Trinidad e Tobago denunciou a Convenção em 26.05.1998, com vigência a partir de 26.05.1999. (OEA. CIDH, 2017).

13 Além disso, a Convenção prevê, em seu Capítulo V, art. 32, os Deveres das Pessoas, no âmbito da Correlação entre Deveres e Direitos, quais sejam: "1. Toda pessoa tem deveres para com a família, a comunidade e a humanidade; 2 . Os direitos de cada pessoa são limitados pelos direitos dos demais, pela segurança de todos e pelas justas exigências do bem comum, numa sociedade democrática". (OEA. CIDH, 2017).

14 Barbados, Guatemala, Trinidad e Tobago formularam reserva a esse artigo, tendo em vista que seus ordenamentos jurídicos internos previam a possibilidade de condenação à pena de morte, sendo posteriormente retirada a reserva apenas pela Guatemala. 0 México fez uma declaração interpretativa no sentido de que não entende que haja obrigação de adotar ou manter em vigor legislação que proteja a vida desde a concepção, vez que a matéria seria de domínio exclusivo dos Estados. (OEA. CIDH, 2017).

15 Dominica fez uma declaração interpretativa ao artigo, de modo que o mesmo não seja interpretado como proibição a castigos corporais, vez que o país tem uma Lei de Castigo Corporal e Lei de Castigo de Menores Delinquentes. (OEA. CIDH, 2017).

16 Dominica e Barbados fizeram reserva ao direito irrenunciável a assistência de defensor proporcionado pelo Estado, nos casos em que o acusado não se defenda sozinho nem nomeie defensor no prazo legal. (OEA. $\mathrm{CIDH}, 2017)$.

17 A Argentina apresentou uma declaração interpretativa desse artigo para que o erro judiciário que implique obrigação de indenizar seja estabelecido por um tribunal nacional. (OEA. CIDH, 2017). 
Proteção da Honra e da Dignidade (art. 11), Liberdade de Consciência e de Religião (art. 12), Liberdade de Pensamento e de Expressão (art. 13), Direito de Retificação ou Resposta (art. 14), Direito de Reuniāo (art. 15), Liberdade de Associação (art. 16), Proteção da Família (art. 17), Direito ao Nome (art. 18), Direitos da Criança (art. 19), Direito à Nacionalidade (art. 20), Direito à Propriedade Privada (art. 21) ${ }^{18}$, Direito de Circulação e de Residência (art. 22), Direitos Políticos (art. 23) ${ }^{19}$, Igualdade Perante a Lei (art. 24), Proteção Judicial (art. 25) e Desenvolvimento Progressivo (art. 26).

Acerca do controle externo exercido pela comunidade internacional, quando um Estado se vincula a uma Convenção e assume os deveres e obrigaçóes daí decorrentes, Piovesan faz os seguintes apontamentos:

Ao acolher o aparato internacional de proteção bem como as obrigaçóes internacionais dele decorrentes, o Estado passa a aceitar o monitoramento internacional, no que se refere ao modo pelo qual os direitos fundamentais são respeitados em seu território. O Estado passa, assim, a consentir no controle e na fiscalização da comunidade internacional, quando, em casos de violação a direitos fundamentais, a resposta das instituiçôes nacionais se mostra insuficiente e falha, ou, por vezes, inexistente. Enfatizese, contudo que a ação internacional é sempre uma ação suplementar, constituindo uma garantia adicional de proteção aos direitos humanos (PIOVESAN, 2003, p. 61).

Nesse sentido, ao se comprometer com a Convenção, o Estado tem o dever de se submeter aos mecanismos de controle por ela previstos.

Para a efetivação de tais direitos, o Pacto cria dois mecanismos de controle: petiçóes e relatórios. As petições são instrumentos de controle que contem denúncias ou queixas de violação da Convenção por um Estado-parte, e serão apresentadas à Comissão ou à Corte, podendo apresentar-se de duas formas que se diferenciam apenas pelos sujeitos que poderão impetrá-las junto à Comissão. As petições gerais (art. 44) são aquelas que podem ser apresentadas por qualquer pessoal ou grupo de pessoas ou entidade não governamental legalmente reconhecida. Por outro lado, as Petiçóes Específicas são aquelas que contem comunicaçôes feitas por um Estado-parte com alegação de violação dos direitos previstos na Convenção por outro Estado-parte (art. 45), sendo analisada somente quando ambos os Estados reconhecem a competência da Comissão para receber esse tipo de comunicação.

Os relatórios se apresentam em momentos distintos na Convenção: a) enquanto função da Comissão Interamericana de Direitos Humanos, que deverá apresentar um relatório anual à Assembleia-Geral da Organização dos Estados Americanos (art. 41, g); b) enquanto obrigação dos Estados-Partes, que deverão remeter à Comissão cópia dos mesmos a serem enviados às Comissões Executivas do Conselho Interamericano Econômico e Social

18 Embora reconheça o Direito à propriedade privada e à indenização justa em caso de desapropriação por motivo de utilidade pública ou interesse social, o Chile se reservou o direito de que a Comissão e a Corte, ao tratarem a questão, não podem pronunciar-se sobre as razões de utilidade pública ou interesse social que tenham sido utilizadas pelo Estado como fundamento para privar a pessoa de seus bens. A Argentina fez reserva indicando que não serão submetidas a revisão questões relativas à política econômica do governo, as causas de utilidade pública e interesse social, nem o que entendam por indenização justa. (OEA. CIDH, 2017).

190 Uruguai formulou reserva em relação a esse artigo, vez que sua Constituição prevê a possibilidade de suspensão da cidadania de pessoas condenadas a pena de reclusão. 0 México também formulou reserva ao artigo, tendo em vista que sua Carta Magna dispõe que ministros dos cultos não terão direitos a voto ativo ou passivo, nem direito a associação com fins políticos. (OEA. CIDH, 2017). 
e do Conselho Interamericano de Educação, Ciência e Cultura (art. 42); e c) enquanto parecer final da Comissão, nos casos em que chegar ou não a uma solução para as petiçóes ou comunicaçóes a ela apresentadas (arts. 48, 49, 50 e 51).

Além desses mecanismos de controle, o Pacto dispóe sobre a competência dos dois órgãos responsáveis por conhecer os assuntos relacionados à Convenção, sendo um de controle administrativo (Comissão Interamericana de Direitos Humanos) e um de controle jurisdicional (Corte Interamericana de Direitos Humanos).

A Comissão é tratada em 18 artigos no texto da Convenção, os quais dispóem sobre sua Organização (arts. 34 a 40), Funçóes (arts. 41 a 43), Competência (arts. 44 a 47) e Processo na Comissão (arts. 48 a 51).

A Comissão será composta por sete membros eleitos pela Assembleia Geral a partir de lista de candidaturas propostas pelos governos dos Estados-membros, não podendo ser composta por mais de um nacional do mesmo Estado, com mandatos de quatro anos, com possibilidade de uma reeleição. A Comissão representará todos os membros da OEA e contará com estatuto e regulamento próprios.

Sua principal função é promover a observância e defesa dos direitos humanos e, para isso, tem como atribuiçóes: estimular a consciência dos direitos humanos nos povos da América, formular recomendaçóes aos governos dos Estados-membros em matéria de direitos humanos, preparar estudos ou relatórios que julgar convenientes para o desempenho de suas funçóes, solicitar informaçóes aos Estados-membros em matéria de direitos humanos, atender às consultas e prestar assessoramento em matéria de direitos humanos aos Estados que lhe solicitarem, atuar com respeito às petiçóes e outras comunicaçóes de sua competência, apresentar relatório anual à Assembleia Geral da OEA.

Possui competência para analisar as petiçóes gerais apresentadas por pessoas, grupos de pessoas ou entidades não governamentais contra Estados-partes e, reconhecida a competência pelos Estados-membros, também para apreciar petiçóes específicas de Estadoparte contra Estado-parte.

O processo perante a Comissão será analisado com mais apuro quando da apresentação dos resultados da análise das petiçóes impetradas enquanto mecanismo de controle previsto na Convenção.

A Corte Interamericana de Direitos Humanos é tratada em 18 (dezoito) artigos, de forma que o texto do Pacto dispóe sobre sua Organização (arts. 52 a 60), Competências e Funçóes (arts. 61 a 65) e sobre a forma como se dá o Processo perante a Corte (arts. 66 a 69).

A Corte será composta por sete juízes, nacionais dos Estados-membros, não podendo haver dois juízes da mesma nacionalidade, que serão eleitos por seis anos, com possibilidade de uma reeleição. O quorum para deliberaçóes na Corte é de cinco juízes e a Comissão comparecerá a todos os casos perante a Corte. A Corte elaborará seu próprio estatuto, que será submetido à aprovação da Assembleia Geral, e contará com regimento próprio.

Sua principal função é conhecer dos casos relativos à interpretação e aplicação das disposiçóes da Convenção.

Somente Estados-partes e a Comissão podem submeter casos à decisão da Corte, sendo necessário para isso que tenha sido esgotado o procedimento de análise perante a Comissão. A Corte só funcionará nos casos em que os Estados-partes tenham reconhecido sua competência, seja de forma incondicional, ou diante de condição de reciprocidade.

Suas decisóes implicam em determinar que se assegure ao prejudicado o gozo do direito ou liberdade violados, que sejam reparadas as consequências da medida ou situação de violação e/ou o pagamento de indenizaçáo, podendo tomar decisões em caráter permanente 
e, anos casos de extrema gravidade e urgência e quando se fizer necessário para evitar danos irreparáveis, poderá tomar medidas provisórias que considerar pertinentes.

Além disso, a Corte poderá ser consultada pelos Estados-membros da interpretação da Convenção e poderá emitir pareceres sobre a compatibilidade de leis internas com o texto do Pacto e, ainda, com a Carta da OEA, a pedido de um Estado-membro.

A sentença da Corte deverá ser fundamentada e terá caráter definitivo e inapelável, podendo haver pedido de interpretação, no prazo de 90 dias, sobre o sentido ou alcance da sentença. Os Estados-partes na Convenção, que aceitarem a competência da Corte, comprometem-se a cumprir suas decisóes, nos casos em que forem partes.

\section{O SISTEMA DE MONITORAMENTO DA CONVENÇÃO AMERICANA DE DIREITOS HUMANOS/1969 E AS PETIÇÕES INDIVIDUAIS EM MATÉRIA DE DIREITOS HUMANOS DAS MULHERES - ANÁLISE DOS RELATÓRIOS (2006-2015)}

Para a análise do sistema de monitoramento da Convenção Americana de Direitos Humanos foram coletados e selecionados dados extraídos dos relatórios anuais da Comissão Interamericana de Direitos Humanos disponibilizados em seu site oficial ${ }^{20}$, conforme a classificação disponibilizada pela própria Comissão, os relatórios são classificados em: a) relatórios apresentados à Assembleia-Geral da OEA (art. 41, g do Pacto), b) relatórios de solução amistosa da demanda (art. 49), c) relatórios em que não se chegou a uma solução amistosa da demanda (art. 50), d) relatórios de arquivamentos (art. 48.1.b) e e) relatórios de admissibilidade das petições submetidas à apreciação da Comissão (arts. 46, 47 e 48) ${ }^{21}$

Além de apresentar a classificaçâo mencionada, os relatórios disponibilizados pela Comissão permitem o acesso a todos os informativos publicados de casos contra os Estados-partes submetidos à competência da Comissão, com fundamento em qualquer das Convençóes para as quais ela seja órgão de controle.

Dessa forma, foi possível selecionar apenas as petições individuais ou queixas impetradas contra o Estado brasileiro, com fundamento em violaçóes contra os direitos previstos no Pacto de San José, entre os anos de 2006 a 2015, em relação a petiçóes em que mulheres figurem na condição de peticionárias ou vítimas, a fim de verificar se o Sistema Regional de Proteção aos Direitos Humanos se apresenta como um mecanismo de proteção mais célere e eficaz que o sistema de proteção nacional.

Nesse sentido, das informações constantes na Tabela 1, é possível extrair que há um grande déficit de publicaçóes por parte da Comissão IDH. Veja-se, por exemplo, que no ano 2006 foram 147 (cento e quarenta e sete) petiçóes com decisóes favoráveis para o início do trâmite, enquanto que foram publicados apenas 56 (cinqüenta e seis) informes de admissibilidade. Da mesma forma, foram 562 (quinhentas e sessenta e duas) decisóes de inadmissibilidade, com a publicação de apenas 14 (quatorze) informes de inadmissibilidade. Ainda mais gritante é o abismo entre o total de casos de mérito para o período analisado (1087) e as publicações de informes de análise de mérito (53).

20 OEA. CIDH. Publicações. Relatórios Anuais. Disponivel em: <http://cidh.oas.org/Publicacoes.htm>. Acesso em: 10 jul. 2015.

21 A Comissão não publica relatórios intermediários acerca do andamento das demandas desde seu protocolamento até a publicação de algum dos relatórios mencionados, o que impossibilita a realização de análise detalhada acerca de elementos referentes aos prazos e duração dos procedimentos na Comissão. 
Ainda em relação à Tabela 1 , no período de 2006-2015 foram recebidas pela Comissão IDH, com atenção ao Brasil, o total de $\mathbf{1 6 . 7 1 0}$ (dezesseis mil setecentas e dez petiçóes), com 1.379 e 1.392 em processo de admissibilidade nos anos de 2014 e 2015, respectivamente. O indicador "Total de decisóes sobre abertura" (Tabela 1, linha 6), apresenta o total de petiçóes que já foram analisadas pela Secretaria da Comissão IDH, desse modo, subtraindose esse valor da quantidade de petiçóes recebidas, tem-se uma lacuna de $\mathbf{6 . 4 9 1}$ (seis mil quatrocentas e noventa e uma) petiçóes que ainda não passaram pelo estágio inicial de análise da Comissão ${ }^{22}$.

TABELA 1 - Panorama Geral das Petiçóes contra o Brasil (2006-2015)

\begin{tabular}{|c|c|c|c|c|c|c|c|c|c|c|}
\hline SITUAÇÃO ANO & ঠัণ & હิ & 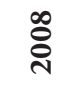 & ฮิ & 올 & స్ & กั้ & 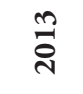 & $\stackrel{4}{\stackrel{4}{4}}$ & $\frac{n}{3}$ \\
\hline Petiçóes Recebidas & 1325 & 1456 & 1323 & 1431 & 1598 & 1658 & 1936 & 2061 & 1758 & 2164 \\
\hline $\begin{array}{c}\text { Petiçóes Pendentes } \\
\text { de Análise Inicial }\end{array}$ & - & - & - & - & - & 6134 & 7208 & 8548 & 9039 & 9673 \\
\hline $\begin{array}{l}\text { Petiçóes com } \\
\text { Decisáo de não } \\
\text { iniciar o trâmite }\end{array}$ & 562 & 880 & 880 & 1395 & 712 & 789 & 674 & 613 & 1039 & 876 \\
\hline $\begin{array}{l}\text { Petiçôes com } \\
\text { decisáo de iniciar o } \\
\text { trâmite }\end{array}$ & 147 & 118 & 118 & 120 & 276 & 262 & 137 & 123 & 284 & 208 \\
\hline $\begin{array}{c}\text { Total de decisóes } \\
\text { sobre abertura }\end{array}$ & 709 & 998 & 998 & 1515 & 988 & 1051 & 811 & 736 & 1323 & 1084 \\
\hline $\begin{array}{c}\text { Informes de } \\
\text { Inadmissibilidade }\end{array}$ & 14 & 14 & 10 & 15 & 10 & 11 & 17 & 9 & 4 & 2 \\
\hline $\begin{array}{c}\text { Informes de } \\
\text { Admissibilidade }\end{array}$ & 56 & 51 & 49 & 62 & 73 & 66 & 42 & 44 & 47 & 42 \\
\hline $\begin{array}{c}\text { Petiçóes em } \\
\text { Admissibilidade }\end{array}$ & - & - & - & - & - & - & - & - & 1379 & 1392 \\
\hline Casos de Mérito & - & - & - & - & - & - & - & - & 576 & 511 \\
\hline $\begin{array}{c}\text { Informes de Mérito } \\
\text { Publicados }\end{array}$ & 8 & 4 & 7 & 13 & 4 & 5 & 1 & 3 & 3 & 5 \\
\hline $\begin{array}{c}\text { Informes de } \\
\text { Soluçáo Amistosa }\end{array}$ & 10 & 5 & 4 & 4 & 11 & 8 & 8 & 6 & 6 & 5 \\
\hline $\begin{array}{c}\text { Petiçốes e casos em } \\
\text { trâmite }\end{array}$ & 1237 & 1251 & 1376 & 1450 & 1584 & 1645 & 1704 & 1753 & 1955 & 1903 \\
\hline $\begin{array}{c}\text { Decisóes de } \\
\text { Arquivamento }\end{array}$ & 27 & 10 & 0 & 20 & 55 & 54 & 42 & 38 & 29 & 107 \\
\hline $\begin{array}{c}\text { Casos enviados à } \\
\text { Corte IDH }\end{array}$ & 14 & 14 & 9 & 11 & 16 & 23 & 12 & 11 & 19 & 14 \\
\hline $\begin{array}{c}\text { Solicitaçóes de } \\
\text { Medidas Cautelares }\end{array}$ & - & - & 301 & - & 375 & 422 & 448 & 400 & 504 & 674 \\
\hline $\begin{array}{c}\text { Medidas Cautelares } \\
\text { Outorgadas }\end{array}$ & 37 & 40 & 28 & 34 & 68 & 57 & 35 & 26 & 33 & 45 \\
\hline
\end{tabular}

Fonte: Elaborada pelas autoras, baseado nos dados estatísticos disponibilizados pela Comissão IDH em: <http://www.oas.org/es/cidh/multimedia/ estadisticas/estadisticas.html>.

Os números deixam claro, em primeiro plano, que a procura pela proteção internacional dos direitos humanos na Comissão não é baixa, pelo contrário, mais de 1.200 (mil e duzentas) petiçóes por ano, no entanto, a resposta que vem sendo dada pela Comissão não atende de forma satisfatória à demanda apresentada.

Embora a própria Comissão, na Tabela 1, faça referência a 532 (quinhentos e trinta e dois) informes de admissibilidade, 106 (cento e seis) de inadmissibilidade, 53 (cinqüenta

22 Para o período analisado, apenas no ano de 2009 o número de decisões sobre abertura de procedimento ultrapassou a quantidade de petições recebidas. 
e três) informes de mérito e 382 (trezentas e oitenta e dois) decisões de arquivamento, nos relatórios anuais publicados foram identificados ao todo, somente 99 (noventa e nove), informes sobre petiçóes impetradas contra o Brasil (Tabela 2 abaixo), sendo 54 (cinquenta e quatro) de admissibilidade, 11 (onze) de inadmissibilidade, 01 (um) de solução amistosa, 05 (cinco) de análise de mérito e 28 (vinte e oito) de arquivamento. Isso significa dizer que, aproximadamente $91 \%$ (noventa e um por cento) de informes náo foram publicados, ou 974 (novecentas e setenta e quatro) informes não localizados nas publicaçóes oficiais da Comissão, e isso, destaque-se novamente, apenas em relação ao Brasil.

TABELA 2 - Petiçóes Gerais contra o Brasil - Informes publicados (2006-2015)

\begin{tabular}{|c|c|c|c|c|c|c|}
\hline \multirow[b]{2}{*}{ ANO } & \multicolumn{6}{|c|}{ SITUAÇÃO } \\
\hline & ADMISSĀO & INADMISSÃO & $\begin{array}{l}\text { SOLUÇÃO } \\
\text { AMISTOSA }\end{array}$ & MÉRITO & ARQUIVAMENTO & $\begin{array}{c}\text { TOTAL } \\
\text { POR } \\
\text { ANO }\end{array}$ \\
\hline 2006 & 06 & 00 & 01 & 01 & 00 & 08 \\
\hline 2007 & 07 & 01 & 00 & 00 & 00 & 08 \\
\hline 2008 & 06 & 00 & 00 & 01 & 00 & 07 \\
\hline 2009 & 07 & 06 & 00 & 02 & 00 & 15 \\
\hline 2010 & 10 & 00 & 00 & 01 & 06 & 17 \\
\hline 2011 & 06 & 00 & 00 & 00 & 03 & 09 \\
\hline 2012 & 08 & 03 & 00 & 00 & 06 & 17 \\
\hline 2013 & 01 & 01 & 00 & 00 & 02 & 04 \\
\hline 2014 & 02 & 00 & 00 & 00 & 00 & 02 \\
\hline 2015 & 01 & 00 & 00 & 00 & 11 & 12 \\
\hline $\begin{array}{c}\text { TOTAL } \\
\text { POR } \\
\text { SITUAÇÃO }\end{array}$ & 54 & 11 & 01 & 05 & 28 & 99 \\
\hline
\end{tabular}

Fonte: Elaborado pelas autoras.

É importante esclarecer que, não necessariamente cada informe é referente a um caso diferente, vez que os casos de solução amistosa, de mérito e de arquivamento podem ser referentes a casos admitidos no mesmo período, o que daria origem a dois informes diferentes para o mesmo caso. Dito isso, caso consideremos que, hipoteticamente, os informes de solução amistosa e de mérito publicados são referentes às petiçôes admitidas no mesmo período, chega-se à conclusão de que, aproximadamente $11 \%$ (onze por cento) dos casos admitidos pela Comissão alcançaram uma resposta definitiva.

Desses 99 (noventa e nove) informes, os que versaram sobre a violação de direitos humanos tendo mulheres como peticionárias ou vítimas totalizaram 18 (dezoito), ou seja, 
cerca de 18\% (dezoito por cento) do total, todas com fundamento no Pacto de São José, conforme detalhado a seguir:

TABELA 3 - Petiçóes Específicas contra o Brasil - peticionárias mulheres (2006-2015)

\begin{tabular}{|c|c|c|c|c|c|c|}
\hline \multirow[b]{2}{*}{ ANO } & \multicolumn{6}{|c|}{ SITUAÇÃO } \\
\hline & ADMISSÃO & INADMISSÃO & $\begin{array}{l}\text { SOLUÇAO } \\
\text { AMISTOSA }\end{array}$ & MÉRITO & ARQUIVAMENTO & $\begin{array}{c}\text { TOTAL } \\
\text { POR ANO }\end{array}$ \\
\hline 2006 & 01 & 00 & 00 & 01 & 00 & 02 \\
\hline 2007 & 01 & 00 & 00 & 00 & 00 & 01 \\
\hline 2008 & 01 & 00 & 00 & 00 & 00 & 01 \\
\hline 2009 & 01 & 00 & 00 & 00 & 00 & 01 \\
\hline 2010 & 03 & 00 & 00 & 00 & 00 & 03 \\
\hline 2011 & 01 & 00 & 00 & 00 & 00 & 01 \\
\hline 2012 & 02 & 02 & 00 & 00 & 01 & 05 \\
\hline 2013 & 01 & 00 & 00 & 00 & 01 & 02 \\
\hline 2014 & 00 & 00 & 00 & 00 & 00 & 00 \\
\hline 2015 & 00 & 00 & 00 & 00 & 02 & 02 \\
\hline $\begin{array}{c}\text { TOTAL } \\
\text { POR } \\
\text { SITUAÇÃO }\end{array}$ & 11 & 02 & 00 & 01 & 04 & 18 \\
\hline
\end{tabular}

Fonte: Elaborado pelas autoras.

A Tabela 3, nesse caso, se mostra ainda mais preocupante que a anterior, representando cerca de $0,10 \%$ (um centésimo) do total de petiçốes submetidas à apreciação da Comissão no período (cf. tabela 1). Além, disso, dentre 18 (dezoito) informes, apenas 01 (um) apresenta resposta definitiva para a demanda, representando pouco mais de $8 \%$ (oito por cento) do total de petiçóes admitidas nas condiçóes descritas nesse período, não se tendo alcançado êxito, até então, na resolução dos casos por intermédio do procedimento de solução amistosa.

Em relação aos relatórios de admissibilidade publicados pela Comissão é importante destacar que seu fundamento encontra-se nos arts. 46.1 do Pacto de San Jose e 31 a 34 do regulamento interno da Comissão, os quais apresentam quatro requisitos para que uma petição possa ser considerada admissível:

a) esgotamento dos recursos internos - leva-se em consideração se foram interpostos e esgotados os recursos de jurisdiçâo interna no Estado-parte, partindo da ideia de que tal requisito funciona como uma garantia para que o Estado-parte tenha oportunidade de resolver os casos internamente e se evite uma interferência arbitrária da jurisdição internacional no ordenamento pátrio. Esse requisito prevê algumas exceçôes que serão tratadas adiante;

b) prazo para apresentação da petiçáo - em regra é de seis meses após a notificação da decisão definitiva de jurisdição interna, no entanto, caso seja aplicada alguma das exceçôes previstas, a petiçẫo deverá ser apresentada em um prazo razoável, a critério da Comissão; 
c) inexistência de duplicidade do procedimento e coisa julgada - na jurisdição internacional;

d) caracterizaçáo de possível violaçáo a dispositivos da Convençáo - nesse primeiro momento (informe de admissibilidade), a Comissão não analisa o mérito da causa, decidindo se de fato restou configurada a efetiva violaçáo de direitos protegidos pela Convenção, mas apenas compara os fatos descritos pelas partes com os dispositivos do Pacto para verificar se aqueles fatos, se confirmados, poderiam resultar em uma possível violação a tais dispositivos, e então, a petição é admitida neste ponto;

Os requisitos a e $\underline{b}$ comportam algumas exceçôes: a) ausência, na legislação interna do Estado-parte, do devido processo legal para a proteção do direito que se alegue tenha sido violado; b) impossibilidade de acesso ou de esgotamento, pelo prejudicado, aos recursos de jurisdiçâo interna; e c) demora injustificada na decisão sobre os mencionados recursos. Destaque-se ainda que nos casos em que o peticionário não cumpre com o requisito de esgotamento dos recursos internos, o prazo para apresentação da petição deverá ser considerado "razoável", por meio de análise discricionária da Comissão que levará em conta a data da violação dos direitos e as circunstâncias específicas do caso concreto.

Quanto aos casos com publicação de informe de admissibilidade, estes serão analisados pormenorizadamente, vez que se dispóe de informaçóes detalhadas sobre o atendimento aos requisitos de admissibilidade indicados na Convenção e no Regulamento Interno da Comissão $\mathrm{IDH}$, os direitos reconhecidamente violados e o lapso temporal decorrido entre os fatos apontados e a publicação dos informes pela Comissão, conforme sintetizado no Quadro 1.

\section{QUADRO 1 - Petiçóes admitidas na Comissáo IDH contra o Brasil referentes a} violaçóes de direitos humanos de mulheres - requisitos de admissibilidade (2006-2015)

\begin{tabular}{|c|c|c|c|c|c|}
\hline \multirow[b]{2}{*}{ Caso } & \multicolumn{4}{|c|}{ Requisitos de Admissibilidade } & \multirow[b]{2}{*}{ Observaçóes } \\
\hline & $\begin{array}{c}\text { Esgotamento } \\
\text { dos Recursos } \\
\text { Internos }\end{array}$ & $\begin{array}{c}\text { Prazo para } \\
\text { Apresentaçáo } \\
\text { da Petiçáo }\end{array}$ & $\begin{array}{l}\text { Inexistência de } \\
\text { Duplicaçáo de } \\
\text { Procedimento } \\
\text { e Coisa Julgada }\end{array}$ & $\begin{array}{l}\text { Caracterizaçáo } \\
\text { de Possível } \\
\text { violaçáo a } \\
\text { dispositivo da } \\
\text { Convençáo }\end{array}$ & \\
\hline Neusa e Gisele ${ }^{1}$ & Náo & Razoável & Sim & Sim & Exceção do art. 46.2.c \\
\hline Marcia Souza $^{2}$ & Náo & Razoável & Sim & Sim & Exceção do art. 46.2.c \\
\hline Margarida Alves ${ }^{3}$ & Sim & Sim & Sim & Sim & - \\
\hline Samantha Nunes ${ }^{4}$ & Sim & Sim & Sim & Sim & - \\
\hline Fatima e Maura 5 & Sim & Sim & Sim & Sim & - \\
\hline $\begin{array}{c}\text { Thalita, Ana e } \\
\text { outros }^{6}\end{array}$ & Náo & Razoável & Sim & Sim & Exceção do art. 46.2.a \\
\hline Rosa e José Luiz ${ }^{7}$ & Sim & Sim & Sim & Sim & - \\
\hline Clelia e Rita ${ }^{8}$ & Náo & Razoável & Sim & Sim & Exceção do art. 46.2.a \\
\hline Nancy e Marcio 9 & Náo & Razoável & Sim & Sim & Exceção do art. 46.2.a \\
\hline Ivete e outros ${ }^{10}$ & Náo & Razoável & Sim & Sim & Exceção do art. 46.2.c \\
\hline M.V.M. e P.S.R. ${ }^{11}$ & Sim & Sim & Sim & Sim & - \\
\hline
\end{tabular}

Fonte: Elaborado pela autora. 
Da leitura dos dados dispostos no Quadro acima, é possível extrair que, mais da metade das petições admitidas pela Comissão o foram em razão da aplicação de alguma das exceções previstas no art. 46.2 da Convenção Americana. Assegurando-se a admissibilidade das demandas nos casos em que não se comprovar, na jurisdição interna, o exercício do devido processo legal para proteger o direito violado (a), ou, ainda, nos casos em que o prejudicado não conseguir acessar ou esgotar os recursos de jurisdição interna (b), ou em que houver demora injustificada na decisão sobre os mencionados recursos (c). Nos casos listados acima, houve a aplicação das exceções previstas nas alíneas "a" e "c" em igual proporção (50\%).

O reconhecimento da aplicação de uma das mencionadas exceçôes para suprir a falta do requisito do esgotamento dos recursos internos atrai, como explicado na exposição sobre o procedimento na Comissão, uma mensuração quanto à razoabilidade do prazo para apresentação da petição à Comissão, situação em que ela levará em consideração a data do fato e as circunstâncias do caso concreto.

Em todos os casos analisados no Quadro 1, a Comissão reconheceu a razoabilidade para fins de admissão da petição.

Para esses casos em que foram reconhecidas algumas das exceçôes anteriormente mencionadas, levando em conta as datas dos fatos, a data dos últimos atos nas jurisdiçóes internas e as datas de recebimento da petição pela Comissão, o tempo médio considerado como razoável ficou em aproximadamente 05 (cinco) anos e 06 (seis) meses (da data do fato à data do último ato praticado na jurisdição interna). Sublinha-se que foi de 05 (cinco) anos a média de tempo decorrido entre as datas dos fatos e os recebimentos das petiçóes pela Comissão.

Interessante verificar, ainda, que, para as petiçôes admitidas pela Comissão, o tempo médio decorrido entre a data do recebimento da petição e a publicação do informe de admissibilidade foi de 06 (seis) anos e 06 (seis) meses, com menor tempo observado no caso de Neusa e Gisele (quadro 7, linha 1), em que decorreram 02 (dois) anos e 10 (dez) meses.

Tal informação pode ser comparada com o tempo previsto pela Convenção Americana e pelo Regulamento da Comissão, cujo prazo máximo previsto para duração do procedimento de apreciação inicial e publicação do informe de admissibilidade é de 10 (dez) meses, já considerados os prazos máximos previstos para prorrogação. Ou seja, a média real da Comissão é aproximadamente $8 \mathrm{x}$ (oito vezes) superior à prevista no texto da Convenção e no Regulamento da Comissão.

Outro ponto a ser destacado em relação ao descumprimento dos prazos previstos para as decisôes da Comissão é a análise do decurso temporal no caso Simone Andre Diniz (único com informe de mérito), cujos fatos ocorreram em 02.03.1997, com petição recebida em 10.10.1997, informe de admissibilidade publicado em 09.10.2002 e informe de mérito em 21.10.2006.

Não é demais relembrar que os prazos previstos pelo Pacto de San Jose e pelo Regulamento Interno da Comissão, para que se finalize o procedimento da análise de mérito, com publicação do informe correspondente, é de 3 (três) anos e 5 (cinco) meses entre a publicação do informe de admissibilidade e o informe de mérito. No entanto, no caso concreto, decorreram 04 (quatro) anos, além da previsão normativa, o que se torna mais grave quando observado que, no caso em tela, não foram efetivados os procedimentos facultativos (audiência, investigação in loco ou coleta de prova testemunhal), o que reduz o tempo máximo previsto para 2 (dois anos) e 5 (cinco) meses.

Para o mesmo caso, do recebimento da petição até a publicação do informe de mérito, decorreram 09 (nove) anos, quando o ideal seria 04 (anos) e 03 (três) meses. 
Por fim, em relação aos direitos alegadamente violados, tanto os mencionados pelos peticionários quanto os reconhecidos pela Comissão quando da publicação dos informes de admissibilidade, é de bom alvitre sinalizar que três situaçóes podem ocorrer: a) a Comissão reconhece a possível violação de todos os dispositivos alegados; b) a Comissão reconhece parcialmente a violação dos dispositivos alegados; e c) a Comissão acrescenta dispositivos não alegados pelo peticionário.

O Quadro abaixo apresenta, de forma simplificada, comparação entre os dispositivos alegados pelos peticionários e aqueles efetivamente reconhecidos pela Comissão.

\section{QUADRO 2 - Petiçóes admitidas na Comissão IDH contra o Brasil - comparação entre os dispositivos mencionados pelo peticionário e os reconhecidos pela Comissáo (2006-2015)}

\begin{tabular}{|c|c|c|}
\hline Caso & $\begin{array}{l}\text { Dispositivos Alegados pelo } \\
\text { Peticionário }\end{array}$ & $\begin{array}{c}\text { Dispositivos Acrescentados pela } \\
\text { Comissáo }\end{array}$ \\
\hline Neusa e Gisele & Arts. 1 e 24 & Arts. 8 e 25 \\
\hline Marcia Souza & Arts. $1.1,2,4,24$ e 25 & Art. 8.1 \\
\hline Margarida Alves & Arts. $1.1,8$ e 25 & - \\
\hline Samantha Nunes & Arts. 1.1, 5.1, 7, 11.1, 19, 24 e 25 & Art. 8.1 \\
\hline Fatima e Maura & Arts. $1.1,8,17,19$ e 24 & Arts. 8.1 e 25 \\
\hline Thalita, Ana e outros & Arts, $\mathbf{4}, \mathbf{5}, 11$ e $\mathbf{2 5}$ & Arts. $1.1,5.1$ e 8 \\
\hline Rosa e José Luiz & Arts. $1.1,4$ e 25 & Arts. 8 e 16 \\
\hline Clelia e Rita & Arts. $\mathbf{1 . 1}, \mathbf{2 , 8 , 2 5}$ e 28 & Art. 21 \\
\hline Nancy e Marcio & $\begin{array}{l}\text { Não fez referência a dispositivos } \\
\text { específicos }\end{array}$ & Arts. $1.1,2,8,21$ e 25 \\
\hline Ivete e outros & Arts. $4,5, \mathbf{8 . 1}, 11$ e $\mathbf{2 5 . 1}$ & Arts. 1.1 e 5.1 \\
\hline M.V.M. e P.S.R & & \\
\hline
\end{tabular}

Fonte: Elaborado pela autora.

Em relação ao caso Nancy e $\mathrm{Marcio}^{23}$, no qual os peticionários não fizeram referência expressa aos dispositivos que entendiam terem sido violados pelo Estado, a Comissáo esclareceu que

Nem a Convenção Americana nem o Regulamento da CIDH exigem que o peticionário identifique os direitos específicos que alega terem sido violados pelo Estado no assunto submetido à $\mathrm{CIDH}$, embora os peticionários possam fazê-lo. Compete à Comissão Interamericana, com base na jurisprudência do Sistema, determinar em seus relatórios de admissibilidade os artigos dos instrumentos interamericanos relevantes que são aplicáveis e, no final, estabelecer se tal disposição foi violada e se os fatos alegados foram comprovados mediante elementos suficientes.

Para os demais casos, como se pode observar, unanimemente foram reconhecidas as possibilidades de violação do art. 25 da Convenção, o qual dispóe sobre a Proteção Judicial,

23 Petição no 341-01/ Informe no 10/12 - Nancy Victor da Silva e Marcio Manoel Praga. Disponivel em: <http://www.oas.org/es/cidh/decisiones/2012/BRADP341-01ES.doc>. Acesso em: 10 jul. 2015. 
ou seja, reconheceram-se a possibilidade de violação ao direito “[...] a um recurso simples e rápido ou a qualquer outro recurso efetivo, perante os juízes ou tribunais competentes [...]", assegurando uma decisão sobre os direitos ante o Estado brasileiro.

Tais violações, nos casos concretos analisados, foram representadas pela demora das autoridades brasileiras em iniciar ou dar seguimento às investigaçôes para apuração das violaçóes de direitos perpetradas contra as vítimas, bem como, pelo atraso na execução de sançóes aplicadas nos casos em que houve a devida análise e julgamento do mérito.

\section{CONSIDERAÇÓES FINAIS}

Desde o final a Segunda Guerra Mundial, os direitos humanos vêm demonstrando uma capacidade impressionante de estabelecer, entre os Estados, parâmetros comuns de comportamento e conduta por meio das declaraçóes e dos tratados internacionais.

Entre os direitos humanos, em geral, destaca-se a evolução dos direitos humanos da mulher, que desde 1975, Ano Internacional da Mulher, vem sendo incorporado às normas de direito internacional público em âmbito dos sistemas de proteção internacional global e regional, das quais são exemplos: a Convenção sobre a eliminação de todas as formas de discriminação contra a mulher/1979 e a Convenção Interamericana para Prevenir, Punir e Erradicar a Violência Contra a Mulher/1994.

Não obstante a existência desse fenômeno, a capacidade de implementação dessas regras e princípios contra os Estados violadores ainda se mostra aquém do desejável, e uma resposta eficaz ainda depende prioritariamente da vontade política e da ordem interna de cada país. Isso significa dizer que: às violaçóes ocorridas dentro dos Estados, segue-se a sua competência primeira na solução dos conflitos.

De outro lado, a estrutura dos sistemas de monitoramento convencional, baseados quase que exclusivamente na figura dos Comitês Internacionais, não possui quase poderes judiciais que os habilitem a sancionar os Estados-Partes, responsáveis pelas violaçóes às Convençóes. Ainda que a Comissão Interamericana de Direitos Humanos possa oferecer recomendaçôes, publicar informes e relatar a situação política e legislativa de cada Estado, o meio mais eficaz para fazer cumprir as obrigaçóes dos tratados, ainda se atém à revisão política, positiva ou negativa, exposta em um fórum internacional.

Diante disso, e tomando os altos índices de violaçóes contra as mulheres pelos/nos Estados em geral, o Sistema Americano de Direitos Humanos, especificamente a Comissão Interamericana, tem procurado avançar na ponderação dos requisitos de admissibilidade das demandas, adotando o "critério de razoabilidade" do prazo como regra, em relação à exceção do requisito do "esgotamento dos recursos internos".

Nesse sentido, a maior aceitação das petições e das queixas individuais pela Comissão passa a repercutir num mais amplo comprometimento dos Estados, com referência às recepçóes/adaptaçóes legislativas, como no caso brasileiro de reconhecimento da natureza "violência sexual contra a mulher" em âmbito doméstico e da adoção de um tipo penal específico: o feminicídio. Não de outro modo, também as políticas públicas foram ampliadas e aprofundadas, como o aumento do número de delegacias e juizados especializados para receber e decidir sobre as denúncias de violência contra a mulher. 


\section{REFERÊNCIAS}

AMARAL, Maia Gelman. A sociedade civil brasileira no monitoramento dos direitos humanos: O Relatório Alternativo. Santa Catarina, Florianópolis. 05 de maio de 2006.

BRASIL. Decreto Legislativo no 22, de 26 de maio de 1992a. Aprova o texto da Convenção sobre Direitos Humanos (Pacto de São José) celebrado em São José da Costa Rica, em 22 de novembro de 1969, por ocasiāo da Conferência Especializada Interamericana sobre Direitos Humanos. Brasília. 1992. Disponível em: <http://legis.senado.gov.br/ legislacao/ListaPublicacoes.action?id=136444>. Acesso em: 20 jan. 2017.

BRASIL. Decreto no 678, de 6 de novembro de 1992b. Promulga a Convenção Americana sobre Direitos Humanos (Pacto de São José da Costa Rica), de 22 de novembro de 1969. Brasília. 1992. Disponível em: <http://www.planalto.gov.br/ccivil_03/ decreto/D0678.htm>. Acesso em: 20 jan. 2017.

COMPARATO, Fábio Konder. A afirmação histórica dos direitos humanos. 3 ed. São Paulo: Saraiva, 2003.

NEGREIROS, Maria de J. Padróes de Acesso à Justiça do Sistema Interamericano de Proteçáo dos Direitos Humanos para as Mulheres Vítimas de Violência. Rio de Janeiro - RJ: PUC, Departamento de Direito, 2010.2. 95p. Disponível em: <http:// www.maxwell.lambda.ele.puc-rio.br/16791/16791.PDF>. Acesso em: 28 mar. 2014.

OEA. CIDH. Publicaçóes. Relatórios Anuais. Disponível em: <http://cidh.oas.org/ Publicacoes.htm>. Acesso em: 10 jul. 2015.

OEA. CIDH. Publicaçôes. Informes Anuais. <http://www.oas.org/es/cidh/informes/ anuales.asp>. Acesso em: 10 jul. 2015.

OEA. CIDH. Publicações. Convenção Americana sobre Direitos Humanos. Disponível em: < https://www.cidh.oas.org/basicos/portugues/d.Convencao_Americana_Ratif.. htm>. Acesso em: 20 jan. 2017.

PIOVESAN, Flavia. Direitos Humanos e o direito constitucional internacional. São Paulo: Max Limonad, 2000.

TRINDADE, Antonio Augusto Cançado. A proteçáo internacional dos direitos humanos: fundamentos jurídicos e instrumentos básicos. São Paulo: Saraiva, 1991.

\section{laná Priscilla de Oliveira Silva}

priscilla.iana@hotmail.com

Graduada em Direito pela FDA/UFAL. Graduada em Serviço Social pela FITS/AL. Bolsista PIBIC 2014-2015 no Projeto As Petições Individuais e o Sistema de Monitoramento dos Tratados de Direitos Humanos de Proteção à Mulher. Graduada em Direito pela FDA/ UFAL. Graduada em Serviço Social pela FITS/AL. Bolsista PIBIC 2014-2015 no Projeto As Petições Individuais e o Sistema de Monitoramento dos Tratados de Direitos Humanos de Proteção à Mulher. 


\section{Alessandra Marchioni}

alemarchioni@hotmail.com

Doutora em Direito, pela UFSC, professora no Curso de Direito da UFAL, coordenadora e orientadora de pesquisa no Núcleo de Estudos em Direito Internacional e Meio AmbienteNEDIMA.

\section{(Footnotes)}

1 Petição no 1068-03 / Informe no 84/06 - Neusa dos Santos Nascimento e Gisele Ana Ferreira. Disponível em: <http://cidh.oas.org/annualrep/2006port/BRASIL.1068.03port. htm>. Acesso em: 10 jul. 2015.

2 Petição no 12.263 / Informe no 38/07 - Marcia Barbosa de Souza. Disponível em: <http://cidh.oas.org/annualrep/2007port/Brasil12.263port.htm>. Acesso em: 10 jul. 2015.

3 Petição no 12.332/ Informe no 9/08- Margarida Maria Alves. Disponível em: <http://cidh.oas.org/annualrep/2008port/Brasil12332port.htm>. Acesso em: 10 jul. 2015. 4 Petição no 337-03/ Informe no 93/09- Samantha Nunes da Silva. Disponível em: <http://cidh.oas.org/annualrep/2009port/Brasil337.07port.htm>. Acesso em: 10 jul. 2015. 5 Petição no 12.378 / Informe no 7/10 - Fatima Regina do Nascimento e Maura Tatiane Ferreira Alves. Disponível em: <http://cidh.oas.org/annualrep/2010port/ Brasil12378port.htm>. Acesso em: 10 jul. 2015.

6 Petição no 1454-06/ Informe no 127/10 - Thalita Carvalho de Melo, Ana Paula Goulart e outros. Disponível em: <http://cidh.oas.org/annualrep/2010port/BRAD145406PO.doc>. Acesso em: 10 jul. 2015.

7 Petição no 265/05 / Informe no 128/10 - Rosa Hernandes e José Luiz Sundermann. Disponível em: <http://cidh.oas.org/annualrep/2010port/BRAD265-05PO.doc>. Acesso em: 10 jul. 2015.

8 Petição no 1140-04 / Informe no 145-11- Clélia de Lourdes Goldenberg e Rita de Cassia. Disponível em: <http://cidh.oas.org/annualrep/2011 port/BRAD1140-04PO.doc>. Acesso em: 10 jul. 2015.

9 Petição no 341-01/ Informe no 10/12 - Nancy Victor da Silva e Marcio Manoel Praga. Disponível em: <http://cidh.oas.org/annualrep/2012port/BRADP341-01PO.DOC >. Acesso em: 10 jul. 2015.

10 Petição no 342-07/ Informe no 79/12- Ivete Jordani Demenek e outros. Disponível em: <http://cidh.oas.org/annualrep/2012port/BRAD342-07PO.DOC >. Acesso em: 10 jul. 2015.

11 Petição no 1279-04/ Informe no 37/13- M.V.M. e P.S.R. Disponível em: <http:// www.oas.org/pt/cidh/decisiones/2013/BRAD1279-04PO.doc>. Acesso em: 10 jul. 2015. 